\title{
The Determination of the Developments of Beehives via Artificial Neural Networks
}

\author{
Raif BAYIR, Ahmet ALBAYRAK
}

\begin{abstract}
Honeybees provide great benefits for people both with the foods they produce and as a pollinator. It is known that they pass the whole year with the foods they collect in spring and summer months. Beekeepers also benefit from the honey produced in these periods. Whether a beehive works adequately or not and its status of development can be understood through the observations by beekeepers. In this study, an Arduino-supported neural network model was developed in order to obtain information about the general situations of beehives. The three-input and three-output neural networks were embedded in a board after the training and testing stage. While temperature, humidity, and weight refer to inputs, good situation, stable situation, and bad situation represent outputs. The real-time model has an accuracy of $99.84 \%$.
\end{abstract}

Keywords: artificial intelligence; intelligent systems; backpropagation; neural networks; embedded systems

\section{INTRODUCTION}

People gain big advantages from natural ecological functions (i.e. ecosystem). Pollination, which occurs directly or indirectly through an insect, may be considered as one of these advantages. $35 \%$ of the foods produced out of plants are obtained via pollination occurring through insects. $75 \%$ of this production includes very important plant species for human beings [1]. The economic return of the pollination through insects is around 153 billion Euros per year across the world [2]. Bees are one of the very important pollinators. It is predicted that honeybees are effective in the pollination of $80 \%$ of agricultural products in Europe [3].

Such products produced by honeybees as honey, royal jelly, beeswax, pollen, bee venom, and bee gum are very important for human life, too. While some products are used in the pharmaceutical industry, some others are used as nutrients due to the enzymes they contain. In addition, some products are used in the cosmetics industry. Thus, it is clear that honeybee keeping has become a large industry [4].

Honeybees meet their energy needs by consuming the juice and honey in the hive in order to adjust the interior of the hive to optimum temperature values. When the ambient temperature goes down to $19{ }^{\circ} \mathrm{C}$, the metabolic rate of the colony rises from $7 \mathrm{~W} / \mathrm{kg}$ to $19 \mathrm{~W} / \mathrm{kg}$ [5]. As a result, the consumption rate of the foods in the hive increases.

One of the best studies explaining the negative effects of global warming and seasonal changes on bees is the one carried out by Bacandritsos et al. in Greece. They investigated sudden collective bee deaths, and found out that 5 different virus species led to these deaths. Among the reasons triggering the formation of viruses were fluctuations in temperature and humidity values [6].

What is meant by neural networks are artificial neural networks produced through the imitation of biological neural networks, which are a combination of many neural cells. Neural networks gain information from the external world or other artificial neurons via simple operations [7].

Development boards are the most preferred boards in the design of the embedded system. These boards, which are low-cost and designed fit-for-purpose, can be used for many different purposes along with additional modules called shield. In general, ARM (Acorn Risc Machine) processors are used in the development boards as they have low energy consumption and are programmed with a few commands.

Beekeepers maintain their hives at the beginning of spring. The hives going through good spring maintenance are likely to be productive in summer months. In the present study, a three-input and three-output neural network model was developed in order to determine the daily performances of honeybees. The developed model was loaded onto the Arduino development board and tested real-timely. This paper includes introduction, the literature review concerning the main topics of the study, the materials and methods employed, the experimental study carried out, and conclusion respectively.

\section{LITERATURE REVIEW}

Artificial neural networks are used effectively in many different applications. The successes of cows in artificial insemination were determined via neural networks, and the results were divided into two different groups (i.e. good and bad) [8]. For classifying the leaves of sunflower, firstly the properties were obtained from the photos taken in the RGB space, and then they were applied to a neural network. Thus, a classification with a success rate of up to $90 \%$ was achieved [9]. Milk productions in different regions were predicted in another study where feed-forward back propagation neural networks were used. In four different regions, the data of 130 farms belonging to the past years were used as input and test data for the neural networks. The neural networks were used successfully with a correct prediction rate of 95 $\%$ [10]. Neural networks were used successfully in the modelling of the flight activities of honeybees in the hive [11]. A neural network model was used for classifying the chemicals in the soil [12]. Çakmak and Yildiz conducted a study through a backpropagation neural network and predicted the drying rate required for drying grapes. Firstly, they developed a mechanism for drying the grapes. The grapes were dried through a solar air collector. It was proved that drying prediction could be made via neural networks, and an alternative approach was presented [13]. 
In recent years, the development boards have been employed in many different applications. Al-Busaidi has designed an education board by using the Arduino development board supported by low-cost Matlab. Robot control is performed via this board. Servo motor and step motor controls are performed by reading various detectors [14]. Another education board with a low-cost design consists of the driving of LED (Light Emitting Diodes) components by PWM (Pulse Width Modulation). This board has been used as a supporting part in various mental learnings [15]. Test arrangements containing the Arduino development board were designed to be used in laboratory practices in order to explain the working structures of solar cells to students better [16]. In addition, some studies were conducted with the Atmega processors used in the Arduino development boards. In one of such studies, a helicopter avoiding barriers was designed [17]. The Arduino processors were used for also vehicle speed control systems [18]. In a study conducted in the field of health, an Arduino-based intelligent hardware was designed to help walking disabled people [19]. Moreover, an Arduino development board whereby simple experiments could be carried out was designed to be used in science education [20]. Used also in the field of remote sensing, the Arduino development boards were utilized as an embedded web server. In this study, temperature value was perceived, and temperature control was performed remotely [21]. The education board with an Arduino processor developed for e-learning environments was used successfully [22]. LilyPad Arduino was used successfully in computer sciences education [23]. The Arduino development board, which is fully compatible with Matlab, allows embedding Simulink model files in it.

\section{MATERIALS AND METHODS}

Developed to gain information about the development of hives without opening them and annoying honeybees, the model produced in the current study included hive weight, humidity rate in the hive, and temperature in the hive considered among the important parameters for the development of beehives. The appropriateness of these three parameters is highly important for a hive's development. Based on these three parameters, some information can be gained in regard to beehives. Such information is as the following;

- Weight contains important information concerning the daily working activity of the hive, honeybees' rates of going for flight, and pollen-nectar collection. If the daily weight increase of a hive is not at the normal level, it becomes likely for the beehive to die out. Food requirement increases as the number of larvae in the hive increases in spring months. Worker bees make more flights in order to meet their food requirements. It should be made sure that larvae feed, and the number of colonies is increased so that enough honey is made in summer months, and winter months are welcomed strongly. In a healthy hive, daily weight increase must be at least $\sim 300$ gr in spring months [24].

- The temperature in the hive must be kept between 30 ${ }^{\circ} \mathrm{C}$ and $34{ }^{\circ} \mathrm{C}$ for the development of the larvae [25]. The humidity rate must be between $20 \%$ and $50 \%$ for the development of honey [26]. For a healthy hive to continue its development and growth, it is of vital importance that the above-mentioned three parameters are kept within the requested ranges.

Developed for gaining information about hives, the system basically consists of three main parts. Fig. 1 presents its block diagram. In the computer environment, the neural network to predict the status of the hive by using such data as temperature, humidity, and weight was trained and tested. To this end, Matlab was utilized. Thanks to the Arduino support, Matlab was loaded into the trained neural network development board. Then this board was put in the appropriate place in the hive through connection to detectors reading temperature, humidity, and weight data in the hive. The energy of the sensors and the board was obtained from the solar panels placed on the hive.

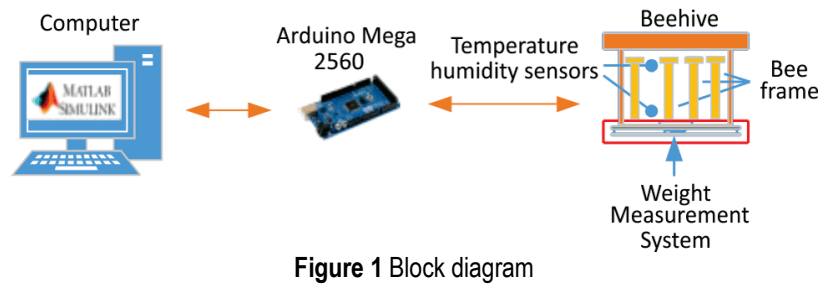

The RISC (Reduced Instruction Set Computing) architecture having an AVR 8 bit microcontroller was used in the production of the development board. It has a low energy consumption level. This development board, which is an open source one, is fully compatible with all operating systems. There are 54 digital input/output pins on the board. 14 of them are PWM. It has 16 analog inputs. It has an operating voltage of 7-12 V, an operating frequency of $16 \mathrm{MHz}$, and a flash memory of $256 \mathrm{~Kb}$. Temperature, humidity, and weight data are read analogously and converted into digital information.

\subsection{The Experimental Measurement for Determination of Beehive Condition}

The weight data required for the training of the network was comprised of the data obtained through 10day measurement. Of the weight data, $70 \%$ was used for training, $15 \%$ for used for testing, and the rest $15 \%$ was used for verification. The training, testing, and validation were obtained from the weight graph provided in Fig. 2.

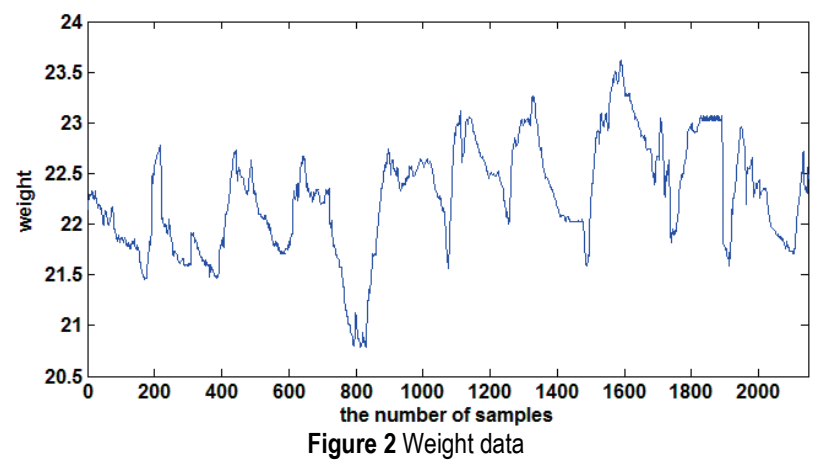

The temperature data consisted of the data obtained through ten-day measurement. For the proper training of the neural network, the data was divided into three 
different sections as in the case of the weight data. The temperature data, which constituted one input of the neural network, is given in Fig. 3.

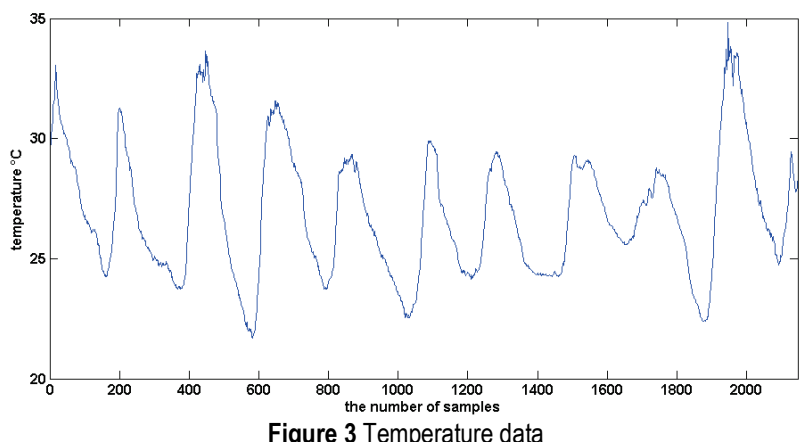

The humidity data, which was the third input of the neural network, also consisted of the data obtained through ten-day measurement. The graph containing the humidity data is provided in Fig. 4. All these three input data were obtained from the beehive measured realtimely.

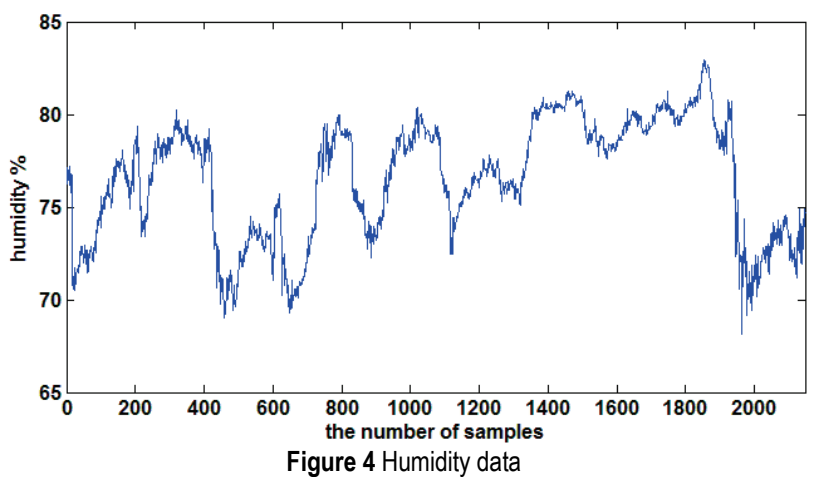

\subsection{Feed-Forward Neural Network}

To understand the hive performance, temperature, humidity, and weight data must be provided as an input for the neural network that can learn like a human being, and such network must be trained. Fig. 5 shows the prepared neural network model.

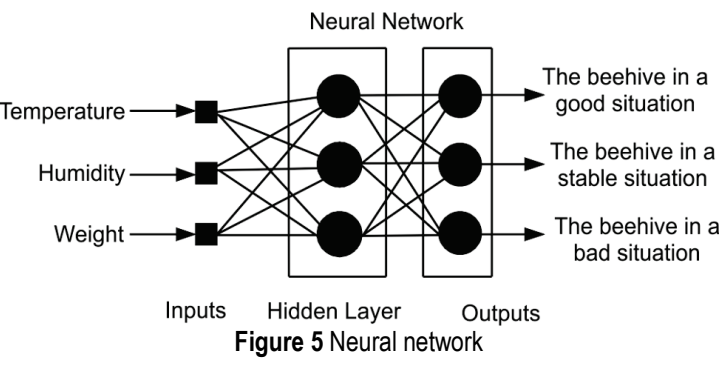

Normalization refers to the conversion of each feature in the dataset. At this stage, the input, output, and test data comprising each feature to be given to the neural network as an input were adjusted to the range of $[-1,1]$ through being subjected to pre-treatment [27]. The equation used in the pre-treatment is given in Eq. (1) below.

$$
\boldsymbol{x}_{i(\mathrm{norm})}=\frac{\boldsymbol{x}_{i}-\boldsymbol{x}_{\min }}{\left(\boldsymbol{x}_{\max }-\boldsymbol{x}_{\min }\right)} .
$$

Here, $\boldsymbol{x}_{i}$ refers to non-normalized feature vector, $\boldsymbol{x}_{\max }$ refers to the feature with the highest numerical value in the dataset, and $\boldsymbol{x}_{\min }$ refers to the feature with the lowest numerical value in the dataset.

Neural networks can learn the complex relationships between the data presented complexly by imitating the human brain. In the present study, a back propagation multilayer perceptron network was used. This neural network consists of an input layer, a hidden layer, and an output layer. The more input is applied to the neural network, the more ganglions are formed in the input. Likewise, the more parameters are taken as an output, the more ganglions are formed. In the hidden layer where the neural network is trained, ganglions are determined by trial and error depending on the degree of difficulty of the problem [13]. The gradient descent algorithm was used in the training of the neural network. The hyperbolic tangent function was employed as the activation function activating the ganglions at certain intervals.

In the multilayer perceptron neural network, the error occurring in the output must expand towards the input. That is why this network is called backpropagation. There are many optimization algorithms used in the backpropagation of the error. In general, the mathematical formula provided in Eq. (2) is used for updating the weights through the backpropagation of the error.

$\boldsymbol{w}(n+1)=\boldsymbol{w}(n)-a(n) \lambda_{j}(\boldsymbol{w}(n))$.

Here, $\boldsymbol{w}(n)$ represents the weight vector at the present step, $a(n)$ stands for the learning parameter, and refers to the Jacobian neural network. $\lambda_{j}$ is known as rank matrix. In the present study, the Levenberg-Marquardt method was used in the backpropagation of the error.

\section{EXPERIMENTAL STUDY}

During the experiment, the analog inputs and digital outputs of the Arduino development board were used. Fig. 6 presents the model file prepared in the Matlab/Simulink environment and embedded in the Arduino development board.

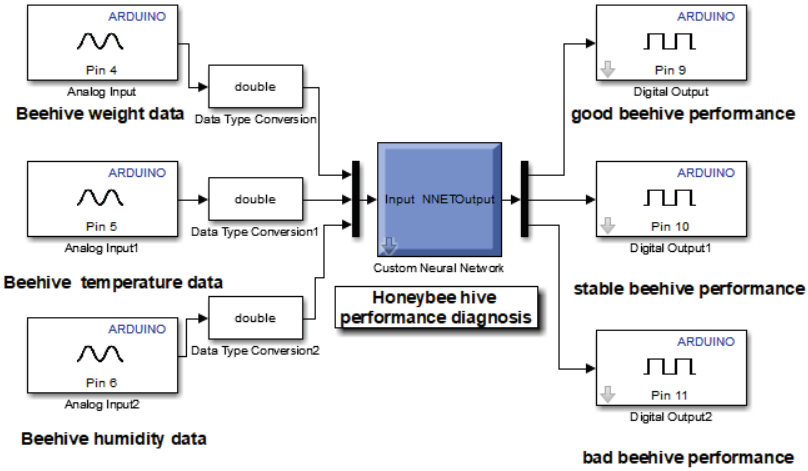

Figure 6 Simulink model file

Since the input of the neural network accepted double data type, the values read from the analog inputs were subjected to type conversion procedure. The appropriate neural network structure had to be determined, and appropriate functions had to be selected for the experiment to be successful. The most appropriate neural 
network model was determined by trial and error among the recommended neural network models whose successes were accepted. Data sets were determined in such a way that each input would be 2148 pcs. in total. The test arrangement is given in Fig. 7.

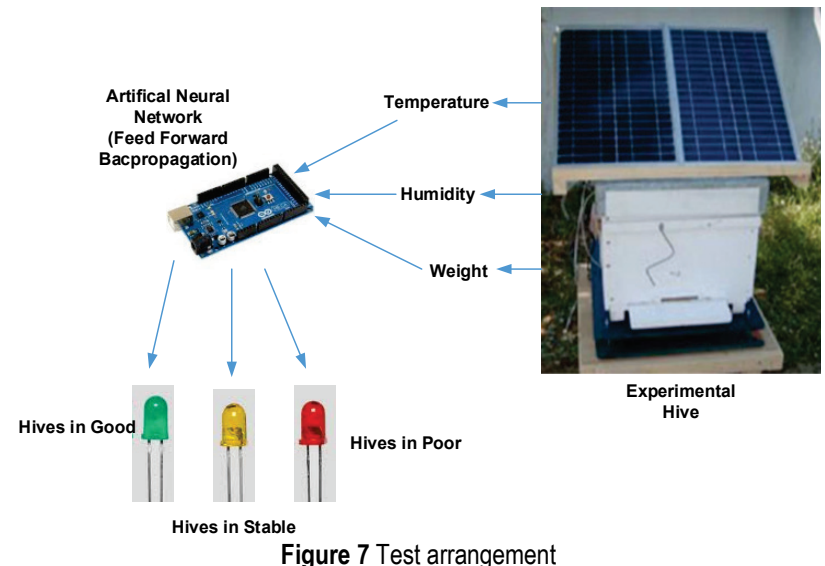

The best result was yielded by the neural network with a single hidden layer having 34 hidden neural cells.

Table 1 The neural network model yielding the best result

\begin{tabular}{|l|l|}
\hline The number of training data & 1503 \\
\hline The number of test and Validation data & 645 \\
\hline Input layer neural cells & 3 \\
\hline Hidden layer neural cells & 34 \\
\hline Output layer neural cells & 3 \\
\hline Training algorithm & Levenberg-Marguardt \\
\hline The number of training epochs & 1000 \\
\hline
\end{tabular}

After the training test was completed, the neural network was tested based on the samples taken from the data representing the entire data space. Then the model embedded in the Arduino board was tested real-timely on the hive given in Fig. 7. Tab. 1 presents details about the neural network.

The performance graph of the neural network finding the best result at epoch 103 is given in Fig. 8.

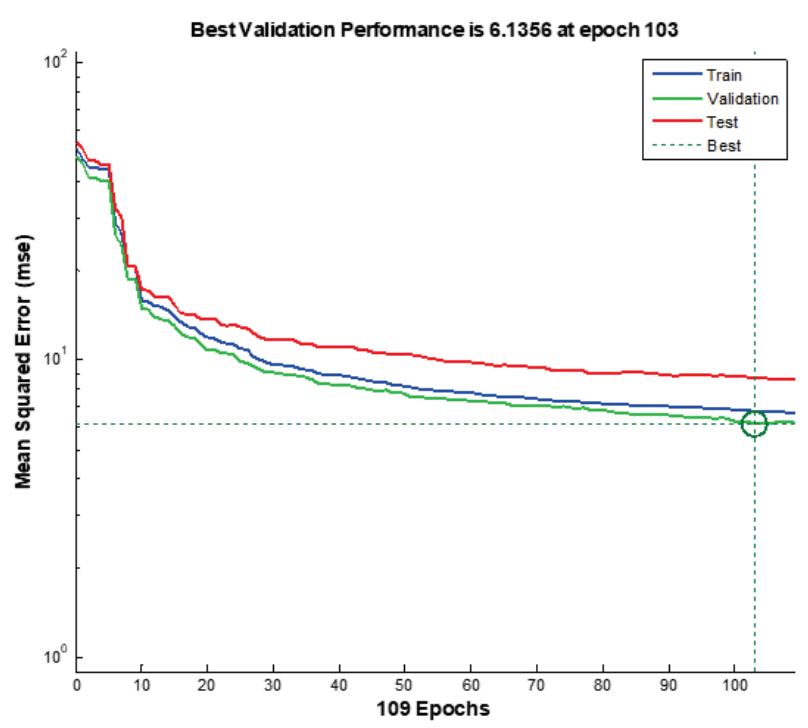

Figure 8 Neural network performance graph

A success of $99.84 \%$ was achieved at the end of the training of the neural network. As a result of the experiments, the best results in education were determined as $99.81 \%, 99.70 \%$ and $99.79 \%$.The warning statuses in the output of the neural network contain valuable meanings for beekeepers. They vary depending on warning status levels. They are as the following;

- The Hive in A Good Situation (Green Led): Bees work enough in the hive. The bees both collect enough food, and establish the temperature and humidity balance through venting enough in the hive. Based on that, some other inferences that can be considered strong assumptions can be made. The queen bee makes enough eggs, and there is no disease, etc. in the hive. Thus, it can be concluded that the hive is healthy and strong.

- The Hive in a Stable Situation (Yellow Led): The required weight increase cannot be reached in the hive. There are fluctuations in humidity and temperature values. Accordingly, beekeepers need to watch the hive and open the hive provided that the above-mentioned situations continue for a long time (for one week).

- The Hive in a Bad Situation (Red Led): Either no weight increase has occurred in the hive, or there has been a decrease in the weight. Temperature and humidity are not at appropriate ranges for the growth of larvae. In this case, beekeepers need to open the hive and intervene immediately. It is very likely that there are adversities like disease. The queen bee does not lay enough eggs, and the hive is about to die out.

\section{CONCLUSION}

The development of bees can be followed closely thanks to the model developed in the present study in order to gain general information about bees without opening beehives. Time-saving is made possible for the beekeepers having hundreds of hives. This model, which gives preliminary information or early diagnosis without opening the hive, may be recommended for the protection of the bee population considering the bee deaths during the observations and investigations carried out by opening the hives. Early diagnosis may be established in regard to diseases or similar situations. It serves as an assistant or expert for those who have just started beekeeping and are not experienced enough.

If more parameters are provided for the neural network as inputs, more outputs may be obtained. As a result, more sensitive diagnoses may be established. The suggestions for the future research to be conducted based on the present one are as follows:

- The system may be improved to make both measurement and prediction real-timely. To this end, the number of parameters measured may be increased (e.g. the density of carbon dioxide, meteorological conditions, etc.), and the system may be tried for a longer period with a stronger embedded development board. In this way, a much better trained neural network may be obtained.

- An early warning system informing beekeepers of emergencies after diagnosis may be developed. In such a mobile-supported application, beekeepers may be informed based on the warning level. 


\section{REFERENCES}

[1] Klein, A. M., Vaissiere, B. E., Cane, J. H., Steffan Dewenter, I., Cunningham, S. A., Kremen, C., \& Tscharntke, T. (2007). Importance of pollinators in changing landscapes for world crops. Proc. R. Soc. B: Biol. Sci. 274, (1608), 303-313. https://doi.org/10.1098/RSPB.2006.3721

[2] Gallai, N., Salles, J. M., Settele, J., \& Vaissiere, B. E. (2009). Economic valuation of the vulnerability of world agriculture confronted with pollinator decline. Ecol. Econ. 68(3), 810-821.

https://doi.org/10.1016/J.ECOLECON.2008.06.014

[3] Breeze, T. D.; Bailey, A. P.; Balcombe, K. G.; Potts, S. G. (2011). Pollination services in the UK: How important are honeybees? Agriculture Eco systems and Environment, 142, 137-143. https://doi.org/10.1016/J.AGEE.2011.03.020

[4] Sudarsan, R., Thompson, C., Kevan, G. P., \& Eberl, J. H. (2012). Flow currents and ventilation in Langstroth beehives due to brood thermo re-gulation efforts of honeybees. Journal of Theoretical Biology, 295, 168-193. https://doi.org/10.1016/J.JTBI.2011.11.007

[5] Southwick, E. E. (1982). Metabolic energy of intact honeybee colonies. Comparative Biochemistry \& Physiology, 71, 277-281. https://doi.org/10.1016/0300-9629(82)90400-5

[6] Bacandritsos, N., Granato A., Budge G., Papanastasiou, I., Roinioti, E., Caldon, M., Falcaro, C., Gallina, A., \& Mutinelli, F. (2010). Sudden deaths and colony population decline in Greek honey bee colonies. Journal of Invertebrate Pathology, 105, pp: 335-340. https://doi.org/10.1016/J.JIP.2010.08.004

[7] Wu, Jian-Da \& Liu, Jun-Ching. (2012). A forecasting system for car fuel consumption using a radial basis function neural network. Expert Systems with Applications, 39, 1883-1888. https://doi.org/10.1016/J.ESWA.2011.07.139

[8] Grzesiak, W., Zaborski, D., Sablik, P., Zukiewicz, A., Dybus, A., \& Szatkowska, I. (2010). Detection of cows with insemination problems using selected classification models. Computers and Electronics in Agriculture, 74, 265273. https://doi.org/10.1016/J.COMPAG.2010.09.001

[9] Arribas, J. I., Sánchez-Ferrero, G. V., Ruiz-Ruiz, G., \& Jaime, G. G. (2011). Leaf classification in sunflower crops by computer vision and neural networks. Computers and Electronics in Agriculture, 78, 9-18. https://doi.org/10.1016/J.COMPAG.2011.05.007

[10] Sanzogni, L. \& Don, K. (2001). Milk production estimates using feed forward artificial neural networks. Computers and Electronics in Agriculture, 32, 21-30. https://doi.org/10.1016/S0168-1699(01)00151-X

[11] Devillers, J., Doré, J. C., Tisseur, M., Cluzeau, S., \& Maurin, G. (2004). Modelling the flight activity of Apis mellifera at the hive entrance. Computers and electronics in Agriculture, 42, 87-109. https://doi.org/10.1016/S0168-1699(03)00102-9

[12] Aitkenhead, M. J., Coull, M. C., Towers, W., Hudson, G., Black, H. I. J. (2012). Predicting soil chemical composition and other soil parameters from field observations using a neural network. Computers and Electronics in Agriculture, 82, 108-116. https://doi.org/10.1016/J.COMPAG.2011.12.013

[13] Cakmak, G. \& Yildiz, C. (2011). The prediction of seedy grape drying rate using a neural network method. Computers and Electronics in Agriculture, 75, 132-138. https://doi.org/10.1016/J.COMPAG.2010.10.008

[14] Al-Busaidi, A. M. (2012). Development of an Educational Environment for Online Control of a Biped Robot using MATLAB and Arduino. Mechatronics-REM, 337-344. https://doi.org/10.1109/MECATRONICS.2012.6451030

[15] Teikari, P., Najjar, R., Malkki, H., Knoblauch, K., Dumortier, D., Gronfier, C., \& Cooper, H. (2011). An inexpensive Arduino based LED stimulator system for vision research. Journal of Neuroscience Methods, 227236. https://doi.org/10.1016/J.JNEUMETH.2012.09.012

[16] Zachariadou, K., Yiasemides, K., \& Trougkakos, N. (2012). A low-cost computer-controlled Arduino-based educational laboratory system for teaching the fundamentals of photovoltaic cells. European Journal of Physics, 33, 15991610. https://doi.org/10.1088/0143-0807/33/6/1599

[17] Divakar, S. (2012). ATmega8 Based Obstacle Avoiding Helicopter. Advanced Materials Research, 403-408, 48884892. https://doi.org/10.4028/www.scientific.net/AMR.403-408.4888

[18] Mohideen, S. K., Sadiq, M. M., Ashwini, G. V., Ajay, P. (2012). A Novel Intelligent Application of Arduino Processor In Automated Vehicle Speed Control System. Advanced Materials Research, 403-408, 5088-5091. https://doi.org/10.4028/www.scientific.net/AMR.403-408.5088

[19] Lengvenis, P., Maskeliunas, R., \& Raudonis, V. (2012). Arduino based Controller for the Smart Assistive Mobility Hardware. Elektronika ir Elektrotechnika, 9, 75-78. https://doi.org/10.5755/j01.eee.18.9.2812

[20] Cavalcante, M. A., Tavolaro, C. R .C., \& Molisani, E. (2011). Physics with Arduino for Beginners. Revista Brasileira De Ensino De Fisica, 33, 4-12. https://doi.org/10.1590/S1806-11172011000400018

[21] Sun, S. H., Jin, Y. S., \& Zhang, W. J. (2011). Design and Simulation of Remote Temperature Monitor and Control System Based on Embedded Web Server. International Conference on Instrumentation, Measurement, Circuits and Systems, 1, 297-300.

[22] Chen, S. N., Chang, R. C., \& Lin, H. J. (2010). Implementation and Application of an Augmented Reality Based Ecology E-learning Platform. Cross-Strait Conference on Information Science and Technology, 784787.

[23] Buechley, L., Eisenberg, M., Catchen, J., \& Crockett, A. (2008). The LilyPad Arduino: Using Computational Textiles to Investigate Engagement, Aesthetics, and Diversity in Computer Science Education. 26 $6^{\text {th }}$ Annual CHI'08 Conference on Human Factors in Computing Systems, 423-432.

[24] Petz, M., Stabentheiner, A., \& Crailsheim, K. (2004). Respiration of individual honeybee larvae in relation to age and ambient temperature. Journal of Comparative Physiology B, 174(7), 511-518. https://doi.org/10.1007/s00360-004-0439-z

[25] Humphrey, J. A. C. \& Dykes, E. S. (2008). Thermal energy conduction in a honey bee comb due to cell-heating bees. Journal of Theoretical Biology, 250(1), 194-208. https://doi.org/10.1016/j.jtbi.2007.09.026

[26] Human, H., Nicolson, S. W., \& Dietemann, V. (2006). Do honeybees, Apis mellifera scutellata, regulate humidity in their nest? Naturwissenschaften, 93(8), 397-401. https://doi.org/10.1007/s00114-006-0117-y

[27] Ahmed, M. A. H., Azah, M., Aini, H., \& Norazila, J. (2010). Artificial Intelligence application to Malaysian electrical power system. Expert Systems with Applications, 37(7), 5023-5031. https://doi.org/10.1016/J.ESWA.2009.12.010

\section{Contact information:}

\section{Raif BAYIR}

Karabuk University, Demir-Çelik Kampüsü

78050 Karabuk / Turkey

rbayir@karabuk.edu.tr

\section{Ahmet ALBAYRAK}

Karadeniz Technical University

61030 Trabzon / Turkey

ahmetalbayrak@ktu.edu.tr 